\title{
Shock Compression of Feldspars ${ }^{1}$
}

\author{
Thomas J. Ahrens \\ California Institute of Technology, Pasadena, California 91109 \\ C. F. Petersen and J. T. Rosengerg \\ Stanford Research Institute, Menlo Park, California 94025
}

\begin{abstract}
Hugoniot data for oligoclase and microcline to 670 and $580 \mathrm{~kb}$ and release adiabat data for oligoclase were obtained by means of the inclined mirror and immersed-foil-reflected-light techniques, respectively. Oligoclase and microcline have Hugoniot elastic limits in the range of 40-55 and 80-85 kb. These limits increase slightly with increasing driving shock pressure. Above the elastic limit, extending to $\sim 300$ and $\sim \mathbf{4 0 0} \mathrm{kb}$, transition regions of anomalously high compression are observed for microcline and oligoclase. These data and the data of McQueen, Marsh, and Fritz for albitite and anorthosite indicate that at successively higher shock pressures within this region, the feldspars gradually transform to a high-pressure, highdensity polymorph. This polymorph probably corresponds to the rutile-like hollandite structure obtained in high-pressure quenching experiments by Kume, Matsumoto, and Koizumi (in $\mathrm{KAlGe}_{3} \mathrm{O}_{8}$ ) and by Ringwood, Reid, and Wadsley (in $\mathrm{KAISo}_{8} \mathrm{O}_{3}$, microcline). In the hollandite structure germanium or silicon is in octahedral coordination with oxygen. The zero-pressure density and the Birch-Murnaghan equation of state parameters for the adiabat and isotherm are calculated for the high-pressure polymorphs of oligoclase, microcline, anorthosite, and albitite. The release adiabat centered at $180 \mathrm{~kb}$ indicates that at this shock pressure some $(\sim 15 \%)$ of the hollandite phase forms but apparently reverts to a lower-density phase on pressure release. Release adiabat curves centered at 272 and $417 \mathrm{~kb}$ and calculated postshock temperatures indicate that material of feldspar composition recovered from meteorite and laboratory impacts is converted to the hollandite structure upon shock compression; upon pressure release this material probably reverts to the low-density maskelynite form.
\end{abstract}

\section{INTRODUCTION}

Previous knowledge of the behavior of feldspars under shock compression has come largely from the Hugoniot data for anorthosite and albitite reported by McQueen et al. [1967] and a few data for various plagioclases reported by Ahrens and Gregson [1964]. Both initial analysis of the plagioclase shock data by McQueen et al. [1967] and subsequent analyses by Wang [1967], Anderson and Kanamori [1968], and Ahrens et al. [1969] have shown that above shock pressures of $\sim \mathbf{4 0 0} \mathrm{kb}$ the plagioclase transforms to a denser, presumably more closely packed, structure. Thermodynamic calculations made by these investigators with the $M c Q u e e n$ et al. [1967] data and auxiliary low-pressure

\footnotetext{
1 Contribution 1563, Division of Geological Sciences, California Institute of Technology, Pasadena, California 91109.
}

Copyright (C) 1969 by the American Geophysical Union. ultrasonic results have yielded estimates of the zero-pressure density of the high-pressure phase of 3.57 to 3.81 for albitite $\left(A n_{12}\right)$ and 3.46 to 3.79 for anorthosite $\left(\mathrm{An}_{\mathbf{}}\right)$. The relatively wide variations in the estimated zero-pressure densities of the high-pressure phases result from differences in the methods and assumptions used in reducing the data. The estimated zero-pressure densities also vary because of the different pressure ranges over which the Hugoniot data are assumed to reflect the pressure-volumeenergy $(P-V-E)$ behavior of the high-pressure phases. The recent results of static high-pressure quenching experiments on the aluminosilicates [Ringwood et al., 1967] and structural analogs [Kume et al., 1966] have demonstrated that under pressure a transformation occurs such that silicon goes from fourfold coordination with oxygen to sixfold coordination with oxygen. The high-pressure quenching experiments indicate that the compound $\mathrm{KAlGe}_{3} \mathrm{O}_{8}$, analogous to potassium feldspar $\left(\mathrm{KAlSi}_{3} \mathrm{O}_{8}\right.$ ), and $\mathrm{NaAlGe}_{3} \mathrm{O}_{8}$, 
analogous to albite $\left(\mathrm{NaAlSi}_{3} \mathrm{O}_{8}\right)$, form dense rutile-like hollandite structures above approximately 35 and $25 \mathrm{~kb}$, respectively. Ringwood et al. [1967] have prepared the hollandite phase of potassium feldspar $\left(\mathrm{KAlSi}_{3} \mathrm{O}_{8}\right)$ above $\sim 120$ $\mathrm{kb}$. This phase has a zero-pressure density of $3.858 \mathrm{~g} / \mathrm{cm}^{3}$. Ahrens et al. [1969] have concluded that the formation of the hollandite-type structures in microcline and albite under shock compression appears likely.

Experiments in which various plagioclases have been recovered from exposure to shock pressures of several hundred kilobars were performed by Milton and DeCarli [1962] and DeCarli and Jamieson [1959]. These experiments, in contrast to the static quenching experiments, yield a glassy amorphous material of plagioclase composition called maskelynite. The
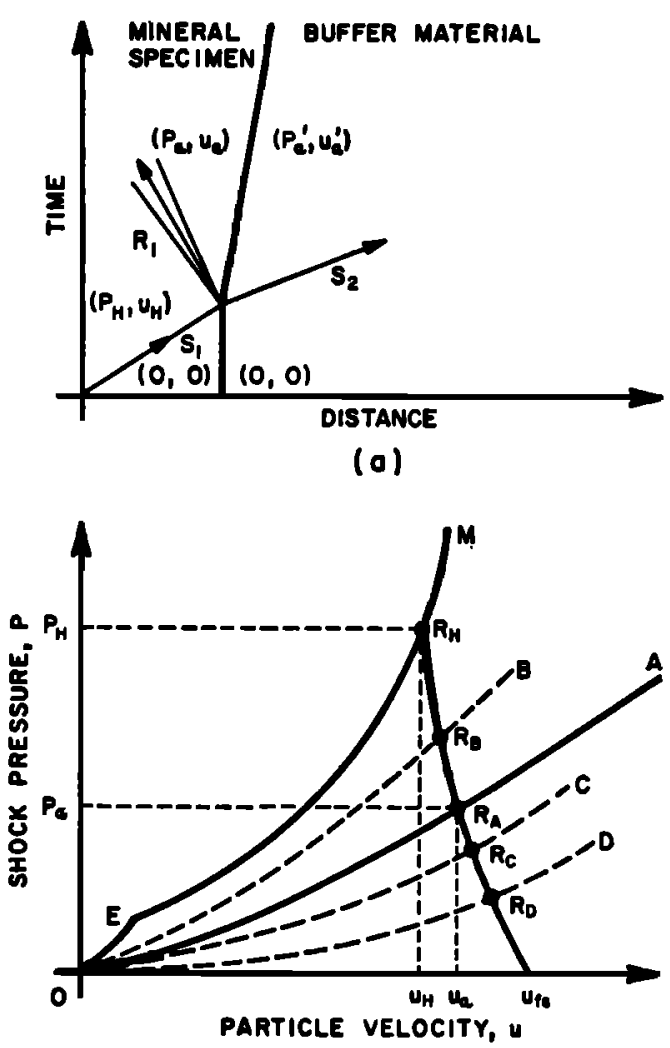

(b)

Fig. 1. Distance-time $(a)$ and shock-pressureparticle-velocity (b) representations of lowimpedance buffer material release adiabat experiment. $O E M$ represents sample Hugoniot; $O B$, $O A, O C$, and $O D$ represent buffer Hugoniots. density (and mean index refraction of this material) is less than that of the corresponding plagioclase but greater than that of the glass produced on melting plagioclase [Duke, 1964; Chao, 1967; Bunch et al., 1967; Stöfler, 1967]. An analogous amorphous phase also exists for potash feldspar (microcline or orthoclase) and, like the amorphous plagioclase, has been found in the vicinity of natural meteorite impact craters and nuclear explosions. The amorphous materials produced from silicates on impact have been named thetamorphic or diaplectic glass by Chao [1967] and von Engelhardt and Stöfler [1968], respectively. Amorphous high-density glass of plagioclase composition has been recognized in several presumably intensity shocked meteorites [Binns, 1967; Duke and Silver, 1967].

The present work was undertaken to examine the relation between the high-density phases that are produced on shock compression to the low-density phases that have been recovered from shock compressed feldspars. To accomplish this, release adiabats, or dynamic unloading pressure-particle velocity curves from a series of high-pressure shock states were obtained for plagioclase samples having an oligoclase composition. The release adiabat data and some additional Hugoniot data for oligoclase and microcline are employed in calculating the pressure-volume-temperature states achieved on shock compression both for feldspars and for the adiabatic release of the oligoclase material.

\section{Experimental Concepts}

Hugoniot states in the feldspars were obtained by using the reflected-light recording techniques described in Ahrens and Gregson [1964]. In the experiments the measured shock transit time through the sample determined the shock velocities, and the velocity associated with the sample and/or driver plate free-surface determined the shock particle velocities. Over much of the pressure range of the present data two shock fronts are formed in the feldspar. As discussed below, the first shock was interpreted as representing the elastic precursor and the second shock represented the deformational or final shock state in the sample. The elastic shock state is determined from the shock velocity, shock-particle velocity (which is assumed to be one-half the free-surface velocity) and the initial density, using the Rankine-Hugoniot con- 
TABLE 1. Analysis of Muskwa Lake Plagioclase (Oligoclase)

J. J. Fahey, analyst (E. C. T. Chao, U. S. Geological Survey, private communication).

\begin{tabular}{lclc}
\hline Oxide & Weight $\%$ & Mineral & Mole \% \\
\hline $\mathrm{SiO}_{2}$ & 63.02 & Albite & 75.13 \\
$\mathrm{Al}_{2} \mathrm{O}_{3}$ & 27.93 & Anorthite & 19.4 \\
$\mathrm{Fe}_{2} \mathrm{O}_{3}$ & 0.22 & Orthoclase & 5.5 \\
$\mathrm{TiO}_{2}$ & 0.01 & Water & $0.13^{a}$ \\
$\mathrm{MnO}$ & 0.001 & & 100.16 \\
$\mathrm{CaO}$ & 3.89 & & \\
$\mathrm{MgO}$ & 0.087 & & \\
$\mathrm{Na}$ & 8.55 & & \\
$\mathrm{~K}_{2} \mathrm{O}$ & 0.95 & & \\
& 104.66 & & \\
& & &
\end{tabular}

a On heating to above $110^{\circ} \mathrm{C} ; 0.03$ mole $\%$ water released on heating to below $110^{\circ} \mathrm{C}$.

servation equations. The deformational shock state is determined with an impedance match solution [Rice et al., 1958] by using the measured second-shock velocity, the density and the particle velocity associated with the elastic shock state, and the driver plate free-surface velocity.

The concept underlying release adiabat measurement may be illustrated by considering an experiment in which a plane shock, $S_{1}$, which induces a known Hugoniot state, $P_{H}, u_{H}$, in the specimen is permitted to reflect at the interface between the specimen and another material called the buffer material (Figure 1). On reflection of the shock $S_{1}$ at the specimen-buffer interface, a shock $S_{2}$ is transmitted into the buffer material, and a rarefaction (pressure release) wave $R_{1}$ is simultaneously reflected back into the specimen. The pressure in the specimen material is reduced adiabatically by $R_{1}$ to a state that lies along the specimen release adiabat passing through the Hugoniot point, $P_{H}, u_{H}$. Because of the boundary condition requiring continuity of pressure and particle velocity at the specimen-buffer interface, the shock pressure and particle velocity $P_{a}^{\prime}$ and $u_{a}^{\prime}$ associated with the shock front $S_{a}$ in the buffer material are the same as the pressure and particle velocity associated with the state $P_{a}, u_{a}$, behind $R_{1}$ in the specimen. Hence determination of the parameters, $P_{a}, u_{a}$, in the specimen reduce to the task of measuring $P_{a}^{\prime}$ and $u_{a}^{\prime}$ associated with $S_{2}$. When a double-shock profile, such as arises from an elastic and a deformational shock, is transmitted from the sample into the buffer, states on the release adiabat centered at each of the two shock states in the sample can, in principle, be obtained by this method.

By repeating the shock reflection experiment by using different buffer materials, with, for example, Hugoniots $O B, O C$, and $O D$ (Figure 1), a series of pressure-particle velocity release states $R_{B}, R_{A}, R_{c}, R_{D}, u_{f \mathrm{~s}}$ is obtained. Here $u_{f}$ represents the free-surface velocity which is measured when no buffer (or air) is placed above the sample. The locus of states $R_{B}, R_{A}, R_{C}, R_{D}, u_{f}$. defines the specimen release adiabat that passes through the Hugoniot state $P_{E}, u_{E}$ in the $P-u$ plane. Experimental details are given in Ahrens and Ruderman [1966].

\section{Hugoniot and Release Adiabat Measurements}

Hugoniot and release adiabat measurements were performed on a single phase oligoclase from Muskwa Lake Quarry, Ontario (Table 1). Hugoniot data were also obtained by using samples of microcline from Ontario, Canada (purchased from Ward's National Science Establishment). Disk-shaped samples of both materials were prepared from cores taken (approximately) perpendicular to ' $c$ ' crystallographic axis. After surface grinding to a fine finish, the sample densities were obtained by measuring the disk dimensions with a micrometer and weighing the samples. For oligoclase the average density obtained was $2.634 \pm 0.004$ $\mathrm{g} / \mathrm{cm}^{3}$, which correlated well with the value $2.648 \mathrm{~g} / \mathrm{cm}^{3}$ obtained by the method of Archimedes. The Archimedes value compares more closely than does the measuring and weighing method value with the theoretical range of densities for oligoclase of 2.64 to $2.67 \mathrm{~g} / \mathrm{cm}^{3}$. For the microcline, measured densities varied from 2.550 to $2.561 \mathrm{~g} / \mathrm{cm}^{\mathrm{a}}$, which agrees closely with the theoretical value of $2.561 \mathrm{~g} / \mathrm{cm}^{3}$.

In the majority of the experiments, plane steady shock waves were obtained in the experimental assemblies (Table 2) on the impact of explosively accelerated flyer plates (Figure 2). As the shock propagates through the driver plate, specimen, and immersed foil cells, the entire assembly is illuminated from above by an 
TABLE 2. Explosive Driver Systems

\begin{tabular}{|c|c|c|c|c|c|c|}
\hline $\begin{array}{c}\text { System } \\
\text { Designation }\end{array}$ & $\begin{array}{c}\text { Explosive } \\
\text { Pad Type, } \\
\text { Thickness, }{ }^{b} \mathrm{~cm}\end{array}$ & Air Gap, cm & $\begin{array}{c}\text { Flyer Plate } \\
\text { Material, } \\
\text { Thickness, cm }\end{array}$ & $\begin{array}{c}\text { Free-Run } \\
\text { Distance, cm }\end{array}$ & $\begin{array}{r}\text { Drive } \\
\text { Mat } \\
\text { Thickn }\end{array}$ & $\begin{array}{l}\text { Plate } \\
\text { erial, } \\
\text { ess, }^{b} \mathrm{~cm}\end{array}$ \\
\hline $\begin{array}{l}\mathbf{A} \\
\mathbf{B} \\
\mathbf{C} \\
\mathrm{D} \\
\mathbf{E} \\
\mathbf{F}\end{array}$ & $\begin{array}{l}\text { Baratol, 5.1 } \\
\text { HMX, 5.1 } \\
\text { HMX, 7.6 } \\
\text { HMX, 10.2 } \\
\text { HMX, 10.2 } \\
\text { Comp. B-3, 3.2 } \\
\text { + Baratol, 5.08 }\end{array}$ & $\begin{array}{l}0.16 \\
0.32 \\
0.16 \\
0.16 \\
0.16 \\
i\end{array}$ & $\begin{aligned} \text { Alum., } & 1.02 \\
\text { Alum,, } & 1.02 \\
\text { Alum., } & 0.64 \\
\text { Alum., } & 0.64 \\
\text { Brass, } & 0.20 \\
i & \end{aligned}$ & $\begin{array}{l}2.54 \\
2.54 \\
1.91 \\
2.54 \\
2.54^{h} \\
i\end{array}$ & $\begin{array}{l}\text { Alum., } \\
\text { Alum., } \\
\text { Alum., } \\
\text { Alum., } \\
\text { Brass, } \\
\text { Alum., }\end{array}$ & $\begin{array}{l}0.32^{c} \\
0.32^{d} \\
0.48^{e} \\
0.48^{e} \\
0.32 \\
2.54\end{array}$ \\
\hline
\end{tabular}

all systems initiated by 20 -cm-diameter explosive plane-wave generator.

- Alum., Brass, and Comp. B-3 designate 2024 aluminum, 346 brass, and composition B-3 explosive, respectively.

$0.48 \mathrm{~cm}$, shots 12965 and 13062 .

d $0.48 \mathrm{~cm}$, shots 13024 and 13040 .

- $0.32 \mathrm{~cm}$, shot 12026 .

f $2.54 \mathrm{~cm}$, shot 12026 .

$0.64 \mathrm{~cm}$, shot 11897 .

$3.81 \mathrm{~cm}$, shot 11898 .

$i$ Explosive in contact with driver plate.

argon explosive light source. The light reflected from the flat and inelined mirrors and from the immersed foil assembly mounted on the driver plate and the sample is recorded as a function of time through several slits. The slits, whose images are swept along and recorded on film, comprise the field of view of a streak camera.

By employing mirrors mounted on the sample and a driver plate, the streak camera records the shock transit time and hence shock velocity in the sample. The intersection speed, or rate of impaction, of the shock-accelerated freesurfaces of the driver plate and sample with the inclined mirrors are used to calculate driver-

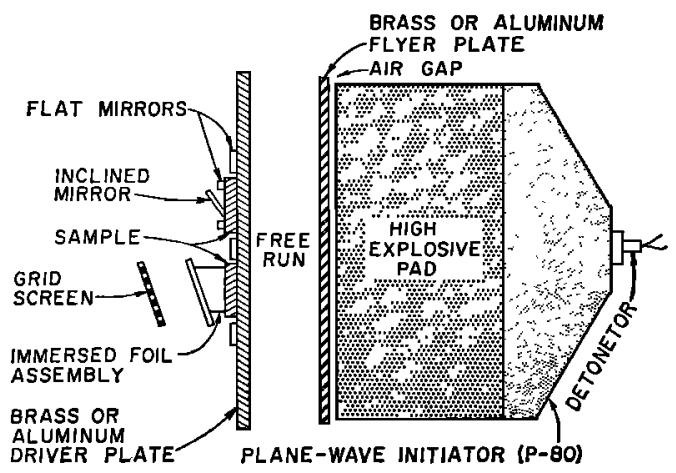

Fig. 2. Side view of plane-wave flyer plate explosive assembly. plate and sample free-surface velocities, respectively. The appropriate formulas are given in Doran [1963] and Ahrens and Gregson [1964]. The initial density and shock and particle velocities associated with the elastic and deformational shock thus determine the shock state in the specimen.

To measure states along the release adiabat, an immersed foil assembly is viewed by a streak camera from the direction normal to the plane of the foil via a slit [Ahrens and Ruderman, 1966]. The slit image on the film plane is again perpendicular to the camera streaking direction. The resulting film record is shown schematically in Figure 3. The shock and particle velocity in the buffer liquid is obtained directly from such a film record. Thus, with a preshot measurement of the liquid density and the variation of index of refraction with pressure, this technique provides release adiabat data without prior knowledge of the liquid Hugoniot.

The shock velocity in the liquid is determined, geometrically, from intersection velocity of a shock wave with the inclined foil and is calculated from

$$
U_{1}=\frac{W}{M} \frac{\sin \alpha_{1}}{\tan \gamma_{01}-\tan \omega}
$$

where $W$ is the streak camera writing rate on 


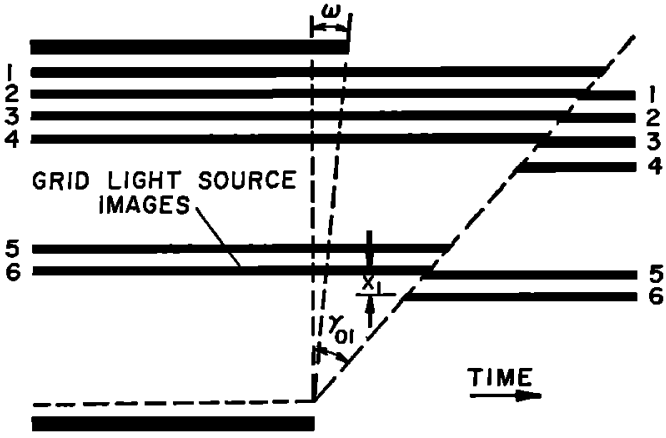

Fig. 3. Diagram of streak camera record, showing film angle and image displacements resulting from shock front propagating within immersed foil assembly.

the film, $M$ is the optical magnification, at and in the plane of the foil, to the film, $\gamma_{01}$ is the angle of the foil disturbance on the film, and $\omega$ is the (usually small) shock tilt as measured on the film. The subscript 1 denotes the first shock front in the liquid.

The particle velocity in the liquid is obtained by measuring the displacement of the image of the grid after the foil has been encompassed by the shock. This displacement results from the foil turning through an angle $\beta$ on achieving the particle velocity of the surrounding shocked liquid. The turning angle $\beta$ is related to the particle velocity of the liquid by

$$
u_{1}=U_{1} \frac{\sin \beta_{1}}{\sin \alpha_{1} \cos \left(\alpha_{1}-\beta_{1}\right)}
$$

The relation of $\beta$ to the displacement of the grid image on the film $x$, to the dimensions of the immersed cell, and to the indices of the refraction of the glass, shocked and unshocked liquid, is given in the appendix.

In using a solid buffer material to obtain release adiabat data, we assume that principal Hugoniot and release adiabats centered along the principal Hugoniot of the buffer material are known and hence a measurement of particle or shock velocity in the buffer determines the buffer shock state. As in the case of liquid buffer, a shock $S_{1}$ originating in the specimen reflects at the specimen-buffer interface (Figure 4). This interaction drives a shock $S_{2}$ in the buffer and a rarefaction wave $R_{1}$, back into the specimen. To obtain the shock pressure $P_{a}^{\prime}=$ $P_{a}$, and the particle velocity $u_{a}^{\prime}=u_{a}$ (state $R_{\varepsilon}$ ) associated with $S_{z}$ and thus also associated with $R_{1}, S_{2}$ is permitted to reflect from the buffer free surface. On reflection of $S_{2}$ at the free surface, rarefaction wave $R_{\mathrm{a}}$ propagates back into the buffer and the buffer free surface achieves the velocity $u_{a f, .}$. The velocity $u_{a f}$. corresponds to the foot of the buffer release adiabat passing through the buffer Hugoniot state $R_{a}$. By measuring the buffer free-surface

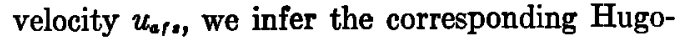
niot state in the buffer $\left(R_{a}\right)$ and hence the pressure and particle velocity associated with a specimen release adiabat state. (Instead of measuring $u_{a f}$ one could, in principle, measure the buffer shock velocity and calculate the buffer shock state from an assumed equation of state.)

In the present experiments commercially pure magnesium in the form of machined plates was used as the buffer witness plate material. Because the shock impedance of magnesium is greater than that of the liquids employed (ethanol and glycerol) but less than that of the specimen, the points on the specimen release adiabat obtained in the $P-u$ plane lie close to the specimen Hugoniot.

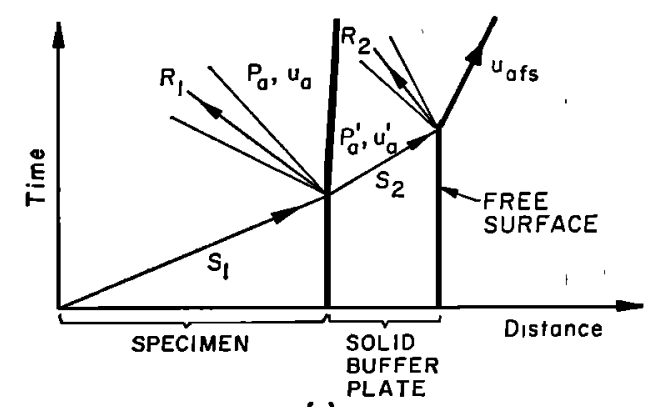

(a)

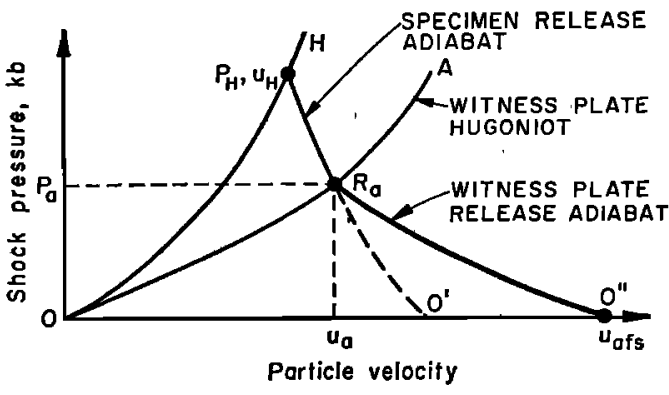

(b)

Fig. 4. Distance-time $(a)$ and shock-pressureparticle-velocity $(b)$ representations of buffer plate release adiabat experiment. 


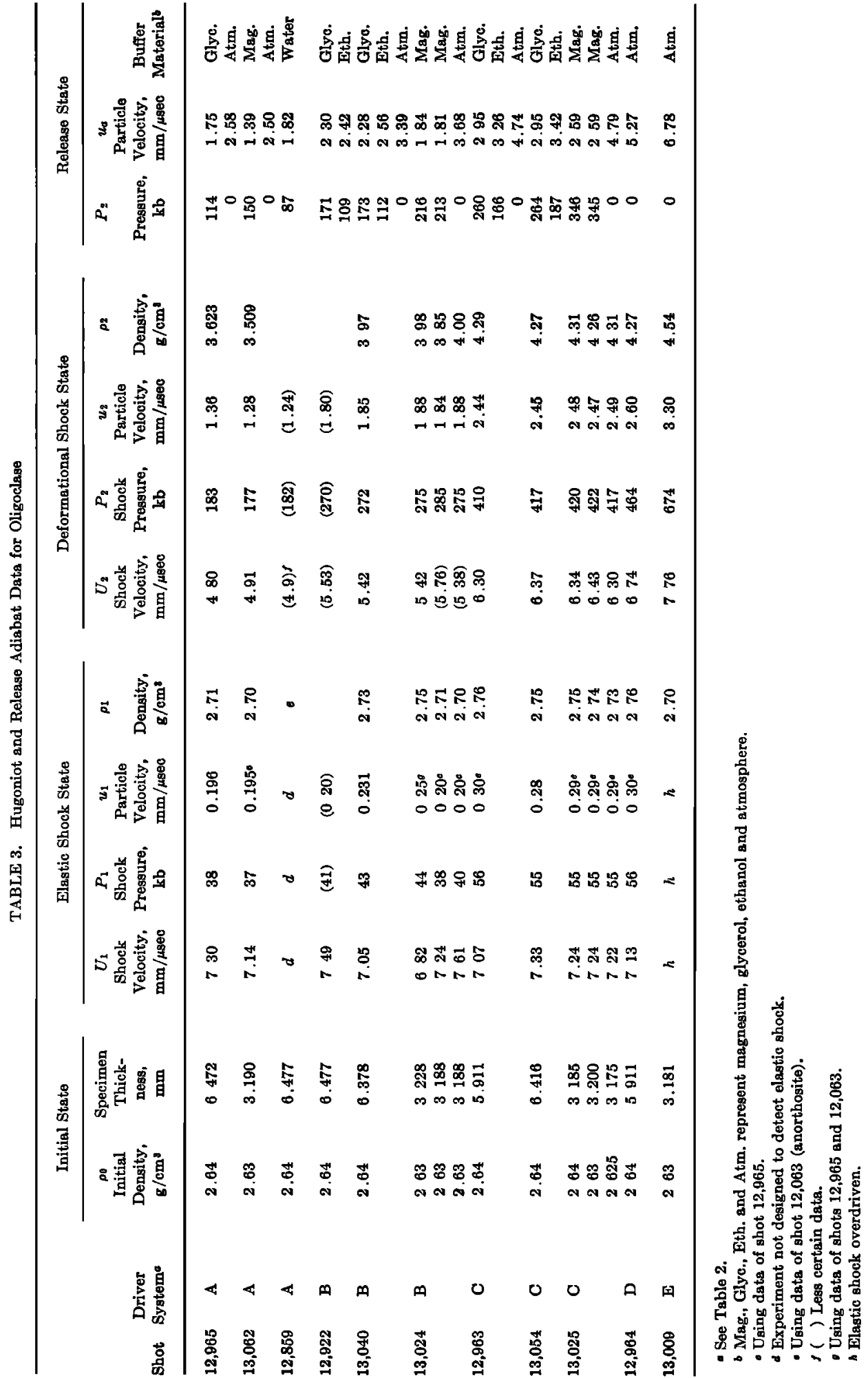




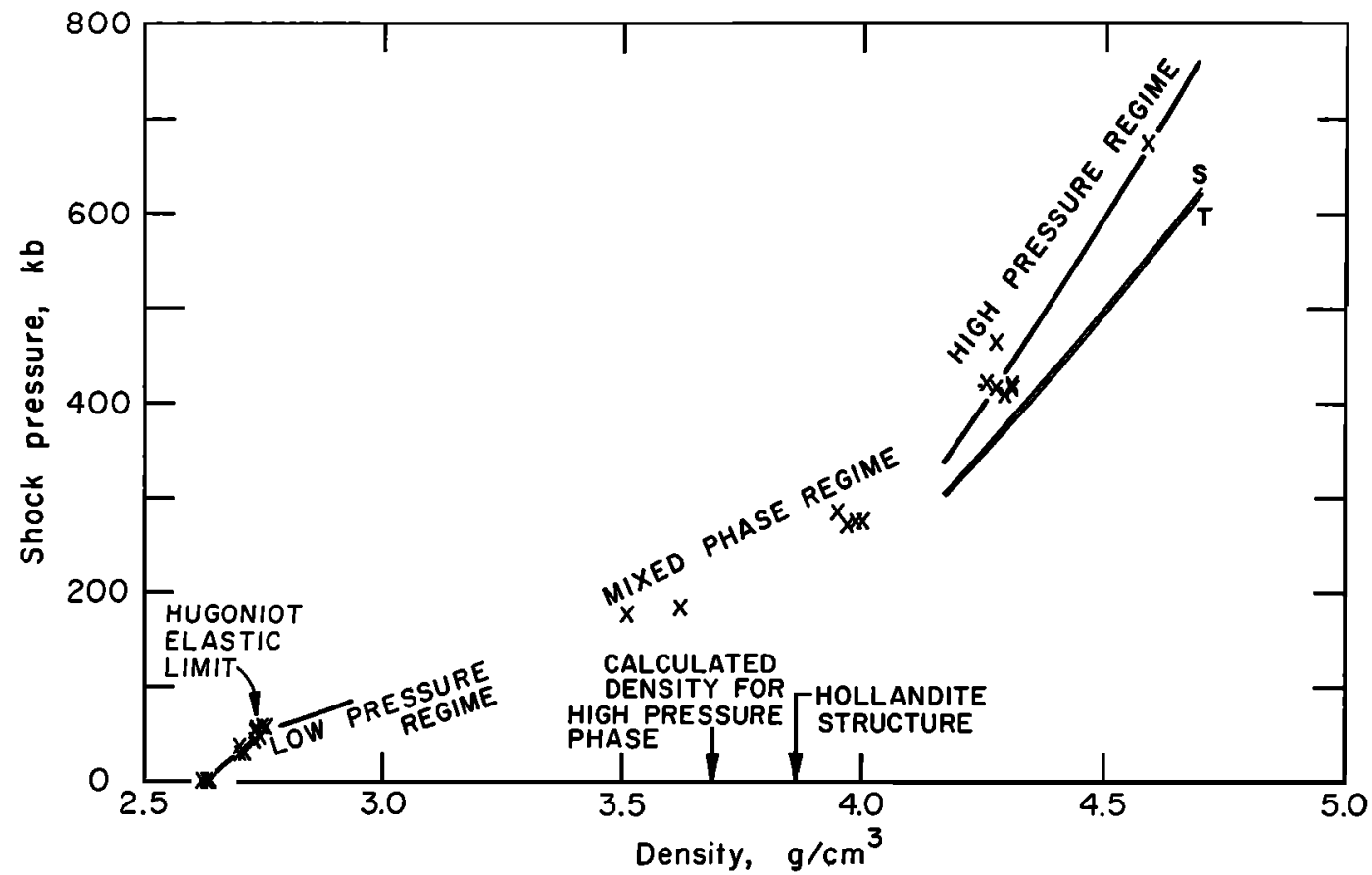

Fig. 5. Hugoniot data, Muskwa Lake oligoclase. Calculated isotherm and adiabat for highpressure phase indicated by $T$ and $S$.

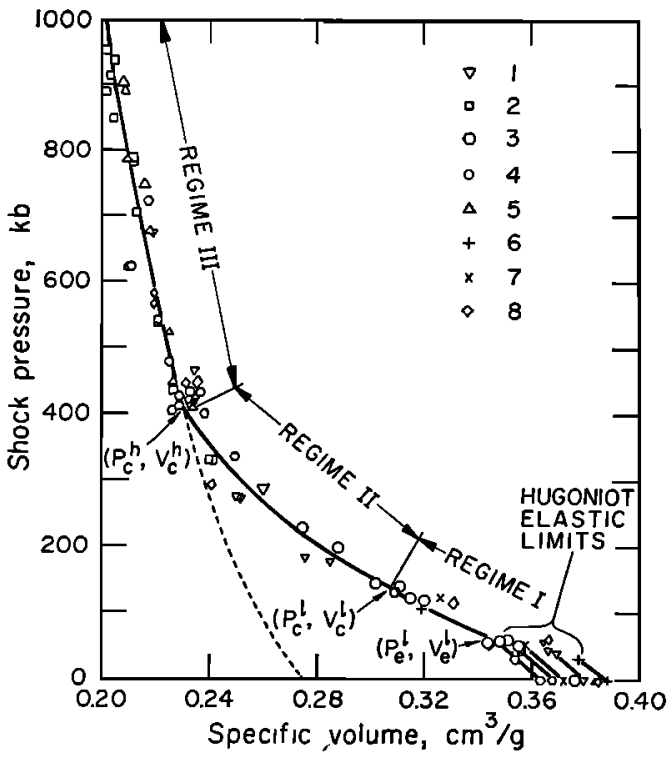

Fig. 6. Hugoniot data for various feldspars (1) oligoclase, (2) anorthosite [McQueen et al., 1967], (3) anorthosite [Ahrens and Rosenberg, 1968], (4) anorthosite [Ahrens and Gregson, 1964], (5) albitite [McQueen et al., 1967], (6) albite [Ahrens and Gregson, 1964], (7) labradorite [Ahrens and Gregson, 1964], (8) microcline.

\section{Experiment Data}

The Hugoniot data for oligoclase (Table 3) are shown in Figures 5 and 6 relative to all the available Hugoniot data for the feldspars. Although there is a slight systematic variation in the Hugoniots of the feldspars (discussed below), a curve may be drawn to represent the range of compositions tested to date. The elastic shock velocities of oligoclase varied from 6.8 to $7.6 \mathrm{~mm} / \mu \mathrm{sec}$. As expected, these velocities, except for one experiment, were slightly higher than the longitudinal ultrasonic velocity of $6.9 \mathrm{~mm} / \mu \mathrm{sec}$ measured along the [001] direction by Alexandrov and Ryzhova [1962]. (For simplicity, Alexandrov and Ryzhova have indexed their plagioclase specimens in the pseudoorthorhombic system.)

In oligoclase the amplitude of the elastic shock (the so-called Hugoniot elastic limit, or HEL) apparently increases with deformational shock amplitude. This effect, called stress relaxation, is known to occur in single-crystal and polycrystalline quartz [Wackerle, 1962; Ahrens and Duvall, 1966]. The HEL varies from about $40 \pm 4 \mathrm{~kb}$ for a 280-kb deformational shock 
to about $55 \pm 1 \mathrm{~kb}$ for a 420 -kb deformational shock. In contrast to the response of quartz and periclase [Ahrens, 1966], no obvious dependence of the HEL with shock propagation path length (varied from 3 to $6 \mathrm{~mm}$ ) is observed.

Above the HEL going from regime I to regime II (Figure 6) the Hugoniot curve for oligoclase indicates a region of anomalous compression. The lower limit of this anomalous region is not certain but a value of $140 \mathrm{~kb}$ was assumed for purposes of shock temperature calculations (see below). Above $400 \mathrm{~kb}$, this anomalous behavior ceases and the Hugoniot and release adiabat curves show normal compressibility and steepness. It thus appears that the region along the Hugoniot above $400 \mathrm{~kb}$ corresponds to the behavior of a new high-pressure phase.

The Hugoniot data for microcline (Table 4, Figure 7) indicates that this mineral has a similar response to that of oligoclase. An elastic shock velocity in the range of 7.09 to 7.56 $\mathrm{mm} / \mu \mathrm{sec}$ is comparable to the zero-pressure elastic wave velocity along the (001) axis of $6.95 \mathrm{~mm} / \mu \mathrm{sec}$ obtained by Alexandrov and Ryzhova [1962]. The Hugoniot elastic limit, as measured in $\sim 3$-mm-thick samples, varied from 79 to $85 \mathrm{~kb}$. Like oligoclase the data indicate a large volume change takes place on shock compression. In microcline these changes seem to occur between deformational shock states of 114 and $296 \mathrm{~kb}$. The analysis of the five highpressure data points with respect to the inferred zero-pressure density and its correlation with the data from static high-pressure experiments is discussed below.

\section{Oligoclase Release Adiabat Data}

The pressure-particle velocity results (Table 3) obtained with the immersed foil and witness plate techniques provide release adiabat data centered along the oligoclase Hugoniot at 180, 270 , and $418 \mathrm{~kb}$ and one of free-surface velocities corresponding to $462 \mathrm{~kb}$. These values are shown in Figure 8. To transform these release curves from the $P-u$ plane into the pressurevolume, it is necessary to use the Riemann integral transformation

$$
V_{a}=V_{1}+\int_{u_{a}}^{u_{1}}\left(\frac{d u_{a}}{d P_{a}}\right) d u_{a}
$$

where $V_{1}$ and $u_{1}$ are the specific volume and 


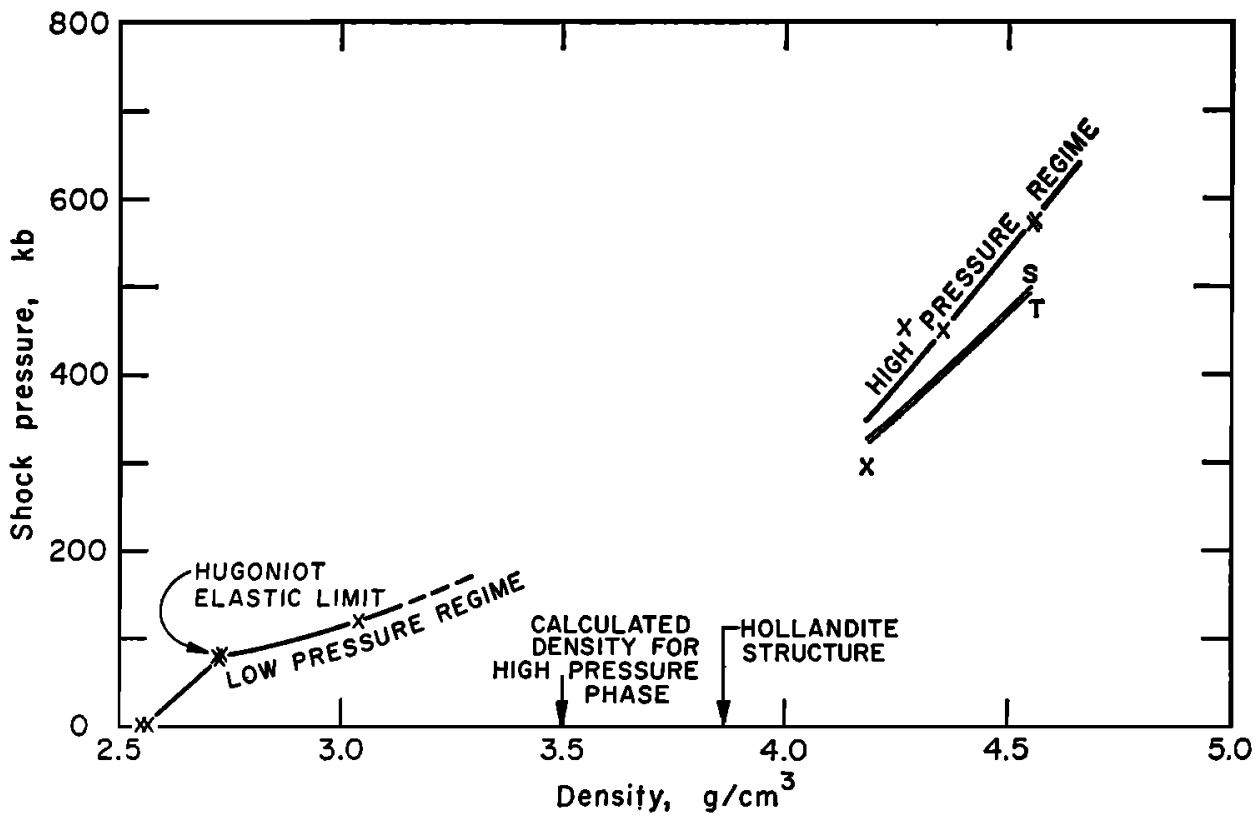

Fig. 7. Hugoniot data, microcline. Calculated isotherm and adiabat for high-pressure phase indicated by $T$ and $S$.

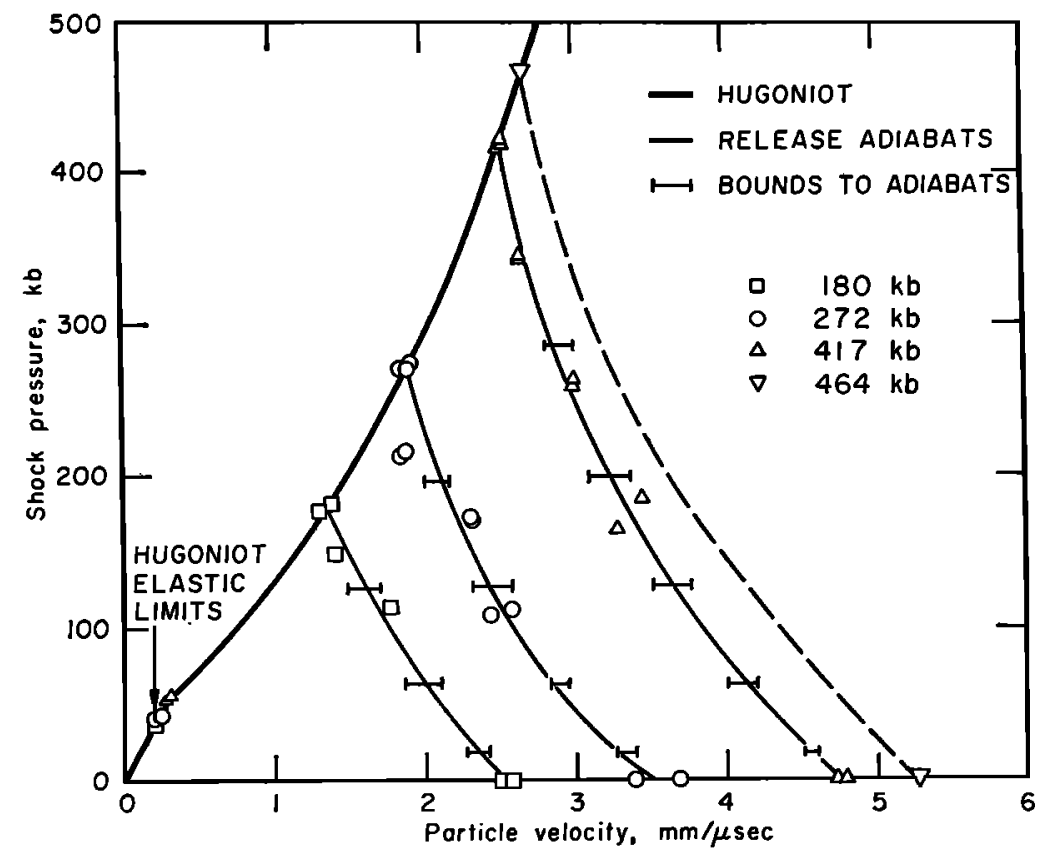

Fig. 8. Shock-pressure-particle-velocity release adiabat curves, Muskwa Lake oligoclase. 


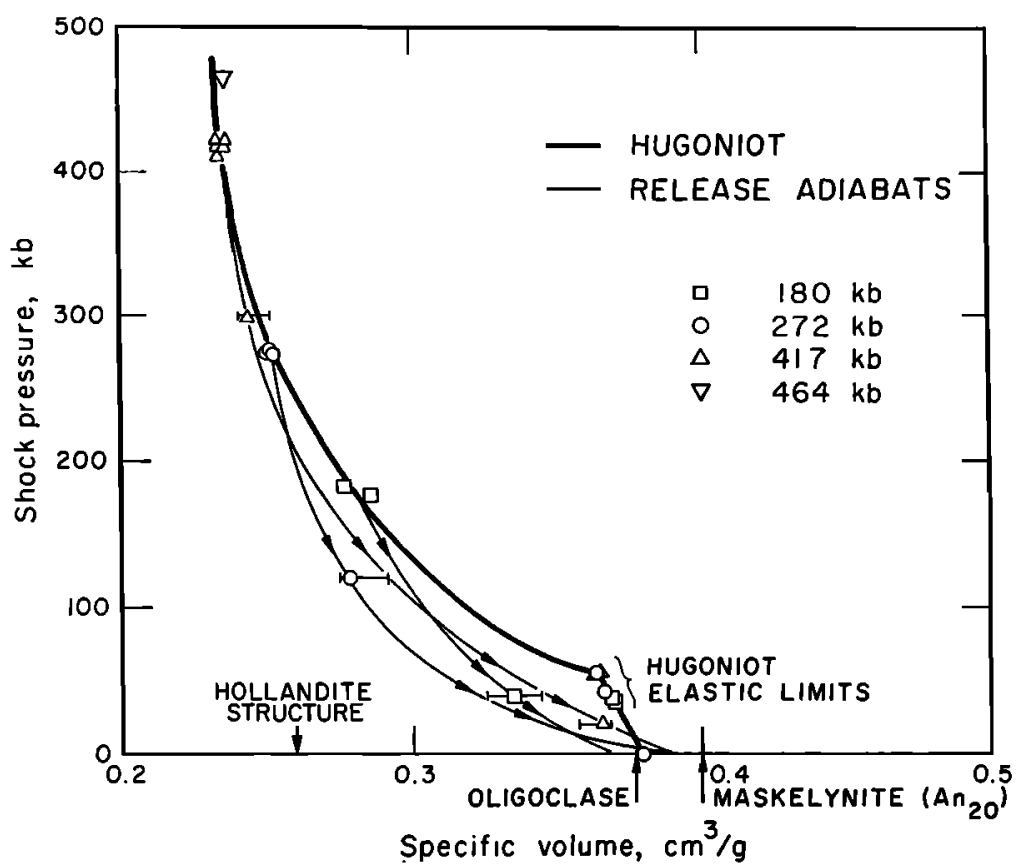

Fig. 9. Shock-pressure-specific-volume release adiabat curves, Muskwa Lake oligoclase.

particle velocity behind the shock and $V_{a}, P_{a}$, and $u_{a}$ are the volume, pressure, and particle velocity at any point along the release adiabat [Rice et al, 1958]. As indicated by the subscript $s$, this transformation is strictly valid only for isentropic processes. We have not established the error involved in using this transformation when entropy is not strictly conserved (because of phase changes taking place along the adiabat), but we believe it is small [Cowperthwaite and Ahrens, 1967].

Pressure-particle velocity release adiabat curves that best fit the data and curves define the largest deviation from these curves are cast in the $P-V$ plane by using equation 3 (Figure 9). Representative uncertainties are indicated by the brackets in Figure 9 and result from the transformation of the maximum deviation curves.

The bulk sound velocity

$$
C_{.}=V(-\partial P / \partial V)_{e^{1 / 2}}
$$

in the high-pressure shock state may be obtained from the measured Hugoniot curve outside the phase transition region and from the release adiabat curves centered at high-pressure shock states. From the Mie-Gruneisen equation of state, the sound speed along the Hugoniot is given by

$$
\begin{array}{r}
C_{H}=V\left\{\left(\frac{\partial P_{H}}{\partial V_{H}}\right)\left[\frac{\left(V_{0}-V\right) \gamma}{2 V}-1\right]\right. \\
\left.+\frac{P_{B} \gamma}{2 V}\right\}^{1 / 2}
\end{array}
$$

[McQueen et al., 1967]. Here $V_{0}$ refers to the initial volume of the starting material, $\left(\partial P_{H} / \partial V_{H}\right)$ is the local slope of the Hugoniot, and $\gamma$ is Grüneisen's ratio $V(\partial P / \partial E)_{\nabla}$. From (5) the values obtained for $C_{B}$ at 180,270 , and 470 $\mathrm{kb}$, the shock pressures of the experimental release adiabats, where calculated (Table 5). If these velocities are compared with the values calculated (equation 4) by using the best fit to the release adiabat $P-V$ data, the velocities obtained from the release adiabat curves in the mixed phase region are much higher than the values obtained from the Hugoniot curve. As expected, the sound speed calculated from the Hugoniot curve according to (5) agrees with that inferred from the release adiabat data only at $417 \mathrm{~kb}$. At this pressure the oligoclase is presumably in the high-pressure region and both the Hugoniot curve and the release adiabat data 
TABLE 5. Bulk Sound Speed along Hugoniot for Oligoclase

\begin{tabular}{|c|c|c|c|}
\hline $\begin{array}{c}\text { Shock } \\
\text { Pressure, } \\
\text { kb }\end{array}$ & $\begin{array}{c}\text { Sound } \\
\text { Speed, } \\
\text { Local Slope } \\
\text { Hugoniot } \\
(5) \\
\mathrm{mm} / \mu \mathrm{sec}\end{array}$ & $\begin{array}{c}\text { Sound } \\
\text { Speed, } \\
\text { Fit to } \\
\text { High- } \\
\text { Pressure } \\
\text { Phase } \\
\text { Data (4), } \\
\text { mm/ } \mu \text { sec }\end{array}$ & $\begin{array}{c}\text { Sound Speed, } \\
\text { Release } \\
\text { Adiabat } \\
\text { Curves (4), } \\
\text { mm/ } / \mu \mathrm{sec}\end{array}$ \\
\hline $\begin{array}{l}180 \\
272 \\
417\end{array}$ & $\begin{array}{l}4.6 \\
5.0 \\
9.0\end{array}$ & $\begin{array}{l}8.2 \\
8.4 \\
8.8\end{array}$ & $\begin{array}{r}5.7 \\
8.3 \\
10.0\end{array}$ \\
\hline
\end{tabular}

are sampling the properties of the high-pressure phase.

The volumes achieved on pressure release that are inferred from the release adiabat experiments (Table 6, Figure 9) indicate that with increasing shock pressure more of the high-pressure (presumably higher density) phase is formed at successively higher pressures. On pressure release some of the high-pressure phase material reverts near zero pressure to material that appears to have a lower density.

For example, the release adiabat centered at $180 \mathrm{~kb}$ indicates that a final zero-pressure den- sity of about $2.71 \mathrm{~g} / \mathrm{cm}^{3}$ (range 2.64 to 2.76 ) is achieved, as compared with 2.64 to $2.65 \mathrm{~g} / \mathrm{cm}^{8}$ for the starting material density. In calculation A (below) partial conversion to a high-pressure phase or phases, with zero-pressure density of $3.64 \mathrm{~g} / \mathrm{cm}^{2}$, is assumed to occur above $140 \mathrm{~kb}$. (A zero-pressure density of $3.70 \mathrm{~g} / \mathrm{cm}^{2}$ for the high-pressure phase was obtained in calculation B.) At $180 \mathrm{~kb}$, about $25 \%$ of the mass of material is transformed to the high-pressure material, according to calculation $A$. If $\sim 25 \%$ mass fraction of high-pressure phase were retained when the material was released to zero pressure from $180 \mathrm{~kb}$, a zero-pressure specific volume of approximately $0.349 \mathrm{~cm}^{3} / \mathrm{g}$ would result. This value compares with a final specific volume of about $0.368 \mathrm{~cm}^{*} / \mathrm{g}$ obtained from the release adiabat curves (representing $\sim 7 \%$ of the high-pressure phase). This result suggests that, for material shocked to about $180 \mathrm{~kb}$, some but not all of the high-pressure phase either reverts to the low-pressure (ordinary) plagioclase phase or reverts to the disordered state represented by maskelynite. The available release adiabat data centered at 272 and $417 \mathrm{~kb}$ indicate that a final zero-pressure density lower than the starting density is achieved when material is shocked to these pressures.

TABLE 6. Release Adiabat Curves

\begin{tabular}{cccc}
\hline & Pressure, kb & Particle Velocity, $\mathrm{mm} / \mu \mathrm{sec}$ & Volume, $\mathrm{cm}^{\mathrm{a}} / \mathrm{g}$ \\
\hline Release from & 180 & 1.32 & 0.280 \\
$180 \mathrm{~kb}$ & 140 & $1.53(1.42-1.59)^{\mathrm{a}}$ & $0.291(0.282-0.298)^{\mathrm{a}}$ \\
& 100 & $1.75(1.60-1.86)$ & $0.303(0.291-0.316)$ \\
& 60 & $2.02(1.88-2.13)$ & $0.321(0.311-0.335)$ \\
& 20 & $2.35(2.27-2.40)$ & $0.349(0.348-0.353)$ \\
Release from & 0 & $1.55(2.52-2.54)$ & $0.368(0.379-0.363)$ \\
$272 \mathrm{~kb}$ & 272 & $2.02(1.90-2.04)$ & 0.252 \\
& 220 & $2.25(2.11-2.36)$ & $0.257(0.253-0.259)$ \\
& 160 & $2.57(2.50-2.73)$ & $0.266(0.261-0.276)$ \\
& 100 & $3.04(3.11-3.12)$ & $0.284(0.286-0.299)$ \\
Release from & 40 & $3.54(3.67-3.39)$ & $0.321(0.349-0.324)$ \\
$417 \mathrm{~kb}$ & 0 & 2.45 & $0.386(0.428-0.342)$ \\
& 417 & $2.71(2.65-2.81)$ & 0.234 \\
& 320 & $3.10(3.00-3.25)$ & $0.241(0.238-0.247)$ \\
& 220 & $3.69(3.55-3.81)$ & $0.256(0.250-0.267)$ \\
& 120 & $4.16(4.03-4.23)$ & $0.291(0.281-0.298)$ \\
& 60 & $4.77(4.76-4.77)$ & $0.329(0.321-0.328)$ \\
& 0 & $0.391(0.413-0.377)$
\end{tabular}

- Values in parentheses indicate maximum range permitted by data. 
The calculations given below indicate that this low density does not result from melting of the low-pressure phase because the postshock temperatures are significantly less than the range of melting temperatures of plagioclase $\left(1118^{\circ}-1553^{\circ} \mathrm{C}\right)$. Rather, the low densities resulting from shock compression to 272 and 417 $\mathrm{kb}$ are due to the instability of the high-pressure phase or phases formed in this pressure regime, and the high-pressure phase(s) reverts to maskelynite. Hence, the maskelynite recovered from the shock experiment represent a reversion product of the high-pressure material. This result is consistent with the bonding differences observed in maskelynite by Bunch et al. [1967] in relation to that of melted plagioclase. The specific volume of maskelynite formed from a plagioclase of oligoclase composition $\left(\mathrm{An}_{20}\right)$ (plotted in Figure 9) inferred from the data of Duke [1964] appears to be slightly greater than, but certainly within the error, of the shock data.

\section{Calculation of Temperatures, Adiabats, AND IsOTHERMS}

Whereas Hugoniot and release adiabat experiments provide the pressure-volume-energy states attained by material on being shocked to high pressure and then monotonically returned to zero pressure, the temperature-time profile must in general be calculated by using additional thermochemical data. The $P-V-T$ history of silicates shocked to various pressure levels is of interest in the study of the shock metamorphism of rock-forming minerals.

For silicates, calculation of shock temperature is challenging because of the transformations to more closely packed structures that take place at elevated pressures and because of the variation of specific heat with temperature and compression that arises from the high Debye temperatures.

For calculation purposes the Hugoniot curves of the feldspar are described in terms of three regimes indicated in Figure 6. Regime I represents the locus of shock states over which the mineral remains in the normal low-pressure phase and consists of the normal elastic and deformational Hugoniot. The superscript $l$ refers to the low-pressure phase. If the material is shocked to a state below $\left(P_{0}^{l}, V_{e}^{l}\right)$, the HEL shock state, a single elastic shock forms. When

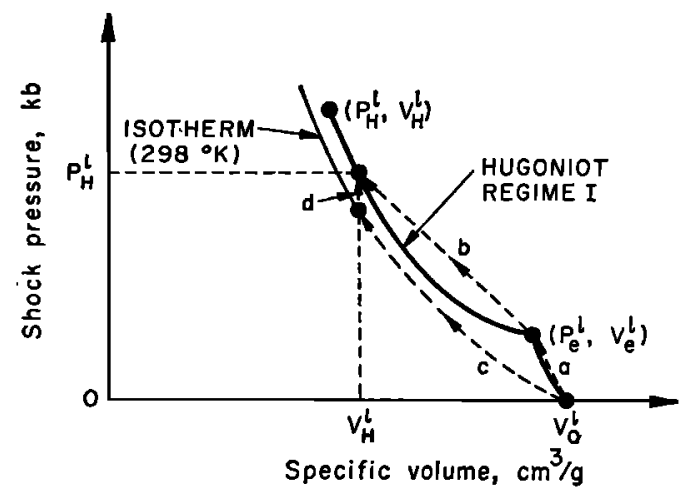

Fig. 10. Hugoniot and thermodynamic paths employed in shock temperature calculations, regime $\mathbf{I}$.

the material is shocked to states above $\left(P_{\bullet}^{l}, V_{\bullet}^{l}\right)$ and below the start of regime II at $\left(P_{0}^{l}, V_{0}^{l}\right)$, an elastic shock of amplitude $P_{a}^{l}$ and a final deformational shock form.

State $\left(P_{0}^{i}, V_{0}^{l}\right)$ represents the onset of the phase transition (or possibly a series of transitions) in which the feldspars transform to more closely packed polymorphs. The transitions (or reactions) that take place within the shocked material are assumed to occur in times comparable to the shock rise time $\left(\sim 10^{-8} \mathrm{sec}\right)$. Since thermal equilibrium, via the conductivity mechanism, is assumed, the domain or particle sizes for each phase must be less than about $10^{-4} \mathrm{~cm}$. For plagioclase, regime II was taken to extend from 140 to $400 \mathrm{~kb}$.

Regime III represents a series of shock states above $P_{0}{ }^{\lambda}, V_{0}{ }^{\lambda}$, in which all the low-pressure material has transformed to the high-pressure phase. Thus, the Hugoniot within regime III is characteristic of the high-pressure phase and the variables associated with this high-pressure phase are identified by the superscript $h$. The calculations describing the temperature along the Hugoniot in all three regimes and the isothermal and the adiabatic pressure-volume curves centered at standard temperature and pressure are outlined below. Two sets of calculations, designated calculation $A$ and calculation $\mathbf{B}$, are outlined. In calculation $A$, which is meant to represent the average properties of a plagioclase, a zero-pressure density of 3.74 $\mathrm{g} / \mathrm{cm}^{\mathbf{3}}$ for the high-pressure phase produced in regime III was assumed. This value was taken from an empirical extrapolation to zero pressure 
of the raw Hugoniot data of McQueen et al. [1967] for albitite and anorthosite and the present data for oligoclase. In the type B calculation, the zero-pressure density and the highpressure phase was constrained to be consistent with Anderson's [1967] seismic equation of state. The type B calculations, performed only for regime III, are summarized below. These are to be reported in detail separately [Ahrens et al., 1969].

Regime $I$. The increase in internal energy of material in shock state $P_{H}{ }^{2}, V_{H}{ }^{2}$ in regime I is given by the Rankine-Hugoniot conservation relation

$$
\begin{aligned}
\Delta E_{\mathrm{I}}= & \frac{P_{a}^{l}\left(V_{0}^{l}-V_{a}^{l}\right)}{2} \\
& +\frac{\left(P_{0}^{l}+P_{H}^{l}\right)\left(V_{a}^{l}-V_{H}^{l}\right)}{2}
\end{aligned}
$$

Here it is assumed that the state $P_{B}{ }^{l}, V_{H}$, is achieved via an elastic shock state [Rice et al., 1958]. The thermodynamic path corresponding to the increase in internal energy $\Delta E_{\mathrm{I}}$, first via an elastic, and then via a deformational shock, is indicated by paths $a$ and $b$ of Figure 10. This increase in internal energy is equated to the increase in internal energy achieved by isothermal compression, at $298^{\circ} \mathrm{K}$, from $V_{0}^{\prime}$ to a final volume of $V_{B}{ }^{2}$ plus heating material at constant volume $V_{B}{ }^{\prime}$ from $T_{0}$ (taken to be $298^{\circ} \mathrm{K}$ ) to the shock temperature $T_{z}$. The energy increase accompanying these two processes, indicated by paths $c$ and $d$ in Figure 10, is represented by

$$
\begin{array}{r}
\Delta E_{\mathrm{I}}=\int_{V_{0} \mathrm{~B}}^{\nabla^{2}}\left(\frac{T \gamma^{2}}{V^{l}} C_{V}^{2}-P\right)_{T_{0}} d V \\
+\int_{T_{0}}^{T_{B}}\left(C_{H}{ }^{l}\right)_{V_{B}} d T
\end{array}
$$

The temperature and volume dependence of $C_{\nabla}$, the specific heat at constant volume, is assumed to be described by the Debye model of the solid [Huang, 1967].

For simplicity we have taken $\gamma / V=b$ (a constant). In calculation $A$ we have assumed this constant to be known for both phases. Here $\gamma$ is Grüneisen's ratio or $V(\partial P / \partial E)_{v}$. Although other, more elaborate forms of $\gamma=\gamma(V)$ are available [Anderson, 1968] the results of the calculations indicate that they are insensitive to reasonable variations in $b$.
Finally, we note that at a given volume the pressure along the Hugoniot $P_{H}{ }^{l}$ exceeds that along the isotherm by

$$
P_{H}^{l}-P_{T}^{l}=b^{l} \int_{T_{0}}^{T B} C_{V}^{l} d T
$$

Eliminating $\Delta E_{\mathrm{I}}$ between equation 6 and 7 and substituting $\left(P_{H}^{2}-P_{z}^{l}\right) / b^{2}$ from (8) into the second term on the right of (7), we have

$$
\begin{aligned}
& \frac{P_{T}^{2}}{b^{2}}+\int_{\nabla_{0}^{2}}^{\nabla_{H^{2}}} P_{T_{0}}{ }^{\prime} d V \\
& =\int_{\nabla_{0} l}^{V_{B^{2}}}\left(T_{0} b^{l} C_{\nabla}^{l}\right)_{T_{0}} d V \\
& +\frac{P_{H}^{l}}{b^{l}}-\frac{P_{0}^{l}\left(V_{0}^{l}-V_{0}^{l}\right)}{2} \\
& -\frac{\left(P_{e}{ }^{l}+P_{H}{ }^{l}\right)\left(V_{e}{ }^{l}-V_{H}{ }^{2}\right)}{2}
\end{aligned}
$$

Since (9) $C_{F}{ }^{2}$ is only a function of volume, (8) and (9) are numerically solved at a series of values of $V^{\prime}$ for $P_{r}{ }^{2}$ and $T_{z}$.

Regime III. In calculation A, the shock temperatures were calculated by employing a scheme very similar to that employed for regime $\mathrm{I}$. The increase in internal energy $\Delta E_{111}$ is again obtained from the Rankine-Hugoniot conservation relation (path $a$, Figure 11). As in regime $I$, this internal energy increase is to be equated with the increase in internal energy achieved by isothermally compressing the high-

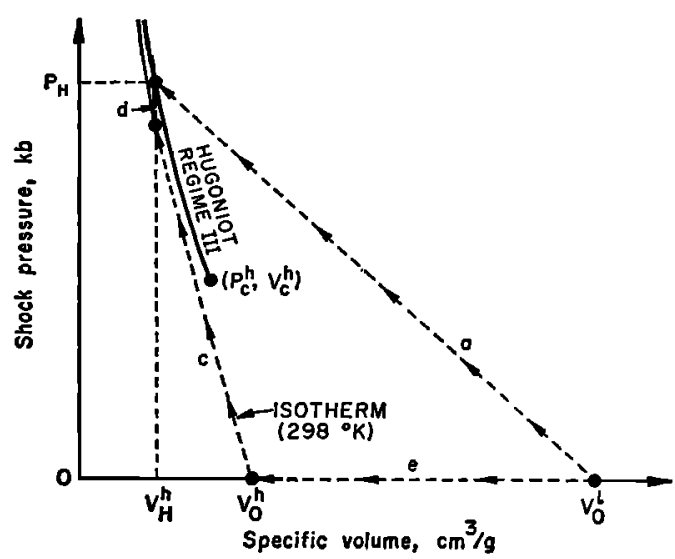

Fig. 11. Hugoniot and thermodynamic paths employed in shock temperature calculations, regime III. 
pressure phase from $V_{0}^{k}$ to $V_{B}{ }^{k}$ (path $c$, Figure 10) and then heating it at constant volume from $T_{0}\left(298^{\circ} \mathrm{K}\right.$ ) to $T_{z}$ (path $d$, Figure 11) plus the difference in internal energy $\Delta E_{\imath-\lambda}$ between the low- and high-pressure phase (path $e$, Figure 11). The internal energy increase associated with paths $c, d$, and $e$ is

$$
\begin{aligned}
\Delta E_{I I I}= & \int_{V_{0}{ }^{h}}^{V_{B^{h}}}\left(T b^{h} C_{V}{ }^{h}-P^{h}\right)_{T_{0}} d V \\
& +\int_{T_{0}}^{T_{B}}\left(C_{B}{ }^{h}\right)_{V_{B}} d T+\Delta E_{l-h}
\end{aligned}
$$

As before, $\Delta E_{\text {III }}$ from the Rankine-Hugoniot equation is substituted into (10) and $\left(P_{H}{ }^{n}-\right.$ $\left.P_{r}{ }^{k}\right) / b^{k}$ is substituted into the second term on the right of $(10)$ to give

$$
\begin{aligned}
\frac{P_{T}{ }^{h}}{b^{h}} & +\int_{V_{0}^{A}}^{V_{B^{A}}} P_{T_{0}}{ }^{h} d V \\
= & \int_{\nabla_{0}{ }^{k}}^{\nabla_{B^{k}}}\left(T_{0} b^{h} C_{V}{ }^{h}\right)_{T_{0}} d V+\Delta E_{l-h} \\
& +\frac{P_{H}{ }^{h}}{b^{h}}-\frac{P_{H}{ }^{h}\left(V_{0}{ }^{l}-V_{H}{ }^{h}\right)}{2}
\end{aligned}
$$

phase at the Hugoniot temperature (ana the Hugoniot volume $V_{H}$ ), must also be known in order to calculate $h$.

To facilitate calculation of $V_{T_{B}{ }^{l}}$ and $V_{T_{B}{ }^{k}}$ at various Hugoniot temperatures it is convenient to use the results from regimes I and III to obtain analytic formulations of the isotherms of both phases with pressure as the independent variable; thus,

$$
V^{l}=V^{l}\left(P_{T_{\bullet}}\right) \quad V^{\AA}=V^{h}\left(P_{T_{0}}\right)
$$

The Hugoniot in regime III is also expressed as

$$
V_{H}=V_{H}\left(P_{H}\right)
$$

Specific volumes of each phase can be related to the Hugoniot temperature by rewriting (12) as

$$
\begin{aligned}
V_{H} & =(1-h)\left[V_{T_{0}}{ }^{2}+\int_{T_{0}}^{T_{H}}\left(\frac{\partial V}{\partial T}\right)_{P_{B}}^{l} d T\right] \\
& +h\left[V_{T_{\bullet}}{ }^{h}+\int_{T_{\bullet}}^{T V}\left(\frac{\partial V}{\partial T}\right)_{P_{H}}^{h} d T\right]
\end{aligned}
$$

which in turn can be written as

$$
\begin{aligned}
V_{H}=(1-h)\left\{V_{T_{\bullet}}{ }^{l}+\int_{T_{\bullet}}^{T_{B}}\left[-b^{2}\left(\frac{\partial V}{\partial P}\right)_{T}^{l} C_{V}{ }^{l}\right] d T\right\} & \\
& +h\left\{V_{T_{\bullet}}{ }^{n}+\int_{T_{\bullet}}^{T_{B}}\left[-b^{h}\left(\frac{\partial V}{\partial P}\right)_{T}^{h} C_{V}{ }^{n}\right] d T\right\}
\end{aligned}
$$

(Actually, a single wave exists only at pressures above $\approx 500 \mathrm{~kb}$; however, the error in neglecting the precursor is small.) Equations 10 and 11 are then solved at a series of volumes for $P_{T}{ }^{n}$ and $T_{H}$.

Regime $I I$. The Hugoniot state $P_{H}, V_{H}$, in regime II represents an aggregate state that is treated as if it is a mixture of the high- and low-pressure phases. Both phases are assumed to be in thermal and mechanical equilibrium. Thus at any point in regime II the specific volume of the aggregate is given by

$$
V_{H}=(1-h) V_{T=T_{H}}{ }^{l}+h V_{T-T_{H}}{ }^{n}
$$

where $h$ is the mass fraction of the material that has been transformed to the high-pressure phase. The value of $h$ varies continuously from 0.0 at $\left(P_{0}^{l}, V_{0}^{l}\right)$ to 1.0 at $\left(P_{0}{ }^{\lambda}, V_{0}{ }^{\lambda}\right)$. At any intermediate point the specific volumes of each
The internal energy of the shock state $\Delta E_{\mathrm{II}}$ is again given by the Rankine-Hugoniot conservation relation (represented by paths $a$ and $b$ in Figure 12). This energy is equated with the sum of the internal energies in each phase on isothermally compressing the material to the Hugoniot pressure $P_{E}$ (relative to the low-pressure phase at $P=0$ ) and then raising the temperature in each phase to the Hugoniot temperature $T_{H}$. For the low-pressure phase these processes correspond to paths $c$ and $d$. For the high-pressure phase, the thermodynamic paths are $c^{\prime}$ and $d^{\prime}$. As in regime III, path $e$ corresponds to the transformation energy at standard conditions. The total internal energy increase for states in regime II is thus composed of five terms: the isothermal compression of both phases to $P_{H}$, the isobaric heating of both phases from $T_{0}$ to $T_{H}$, and a transformation energy term. These are written as 


$$
\begin{aligned}
& \Delta E_{\mathrm{II}}=\left[(1-h) \int_{0}^{P_{H}}\left(\frac{\partial V}{\partial P}\right)^{l}\left[T b^{l} C_{V}{ }^{l}-P_{r_{\bullet}}{ }^{l}\right] d P\right]_{T_{\bullet}} \\
& +h\left[\int_{0}^{P^{n}}\left(\frac{\partial V}{\partial P}\right)^{h}\left[T b^{h} C_{V}^{h}-P_{T_{0}}^{h}\right] d P\right]_{T} . \\
& +(1-h) \int_{T_{0}}^{T_{B}}\left[C_{V}{ }^{l}-b^{l a} C_{V}^{l 1} T\left(\frac{\partial V}{\partial P}\right)_{T}^{l}\right]_{P_{B}} d T \\
& +h \int_{T_{0}}^{T_{B}}\left[C_{V}{ }^{h}-b^{h 3} C_{V}^{{ }^{h}} T\left(\frac{\partial V}{\partial P}\right)_{T}^{h}\right]_{P_{B}} d T+h \Delta E_{l-h}
\end{aligned}
$$

Substituting for $\Delta E_{\mathrm{II}}$ in (16) and regrouping terms, we have

$$
\begin{aligned}
& \frac{\left(P_{H}+P_{\bullet}^{l}\right)}{2}\left(V_{\bullet}^{l}-V_{H}\right) \\
& +\frac{P_{0}^{l}\left(V_{0}^{l}-V_{e}^{l}\right)}{2}-h \Delta E_{l-h}+(1-h) \int_{0}^{P_{B}}\left(\frac{\partial V}{\partial P}\right)_{T_{0}}^{l}\left[P_{T_{0}}^{l}-T_{0} b^{l} C_{V^{l}}^{l}\right]_{T_{0}} d P \\
& +h \int_{0}^{P_{B}}\left(\frac{\partial V}{\partial P}\right)_{T_{0}}^{h}\left[P_{T}-T_{0} b^{h} C_{V}^{{ }^{h}}\right]_{T_{0}} d P=(1-h) \int_{T_{0}}^{T_{B}}\left[C_{V}^{l}-b^{l \cdot} C_{V}{ }^{l \cdot} T\left(\frac{\partial V}{\partial P}\right)_{T}^{l}\right]_{P_{B}} d T \\
& +h \int_{T_{\mathrm{Q}}}^{T_{H}}\left[C_{V}^{h}-b^{h \cdot} C_{V}^{{ }^{n}} T\left(\frac{\partial V}{\partial P}\right)_{T}^{h}\right]_{P_{H}} d T
\end{aligned}
$$

The isothermal compressibility is assumed to change (increase) slowly with increasing temperature. Equations 15 and 17 are numerically solved to yield $h, T_{H}$, at a series of $P_{H}, V_{E}$, states in regime II.

The type B calculations differ critically from those of type $A$ in that we attempt to determine the density at $25^{\circ} \mathrm{C}$ and $P=0$ of the high-pressure phase (which presumably would be metastable under these conditions). The initial density was obtained by constraining the adiabat of the high-pressure material, centered at $25^{\circ} \mathrm{C}$ and $P=0$, such that it exactly satis-

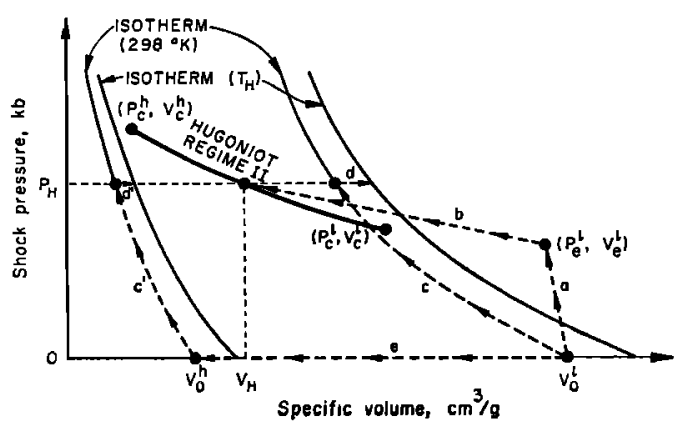

Fig. 12. Hugoniot and thermodynamic paths employed in shock temperature calculations, regime II. fies Anderson's [1967] seismic equation of state (at $25^{\circ} \mathrm{C}$ and $P=0$ )

$$
\rho_{0}{ }^{h} / \bar{M}=0.048\left(K_{s} \rho_{0}{ }^{h} \times 10^{10}\right)^{0.323}
$$

Here $\bar{M}$ is the mean atomic weight and $K$, is the adiabatic bulk modulus at zero pressure. Details are given in Ahrens et al. [1969].

The calculated temperatures for oligoclase for the three regimes are plotted in Figure 13. Shock temperatures, isotherms, and adiabats for regime III are given in Table 7 . Bounds on the postshock temperature achieved along the various experimental release adiabat curves are based on the type A calculations for regime II and III (Table 8) and were calculated under the assumption of isentropic expansion from the shock state; they probably represent an upper limit to the temperature. As pointed out above, the postshock temperatures are far below the zero-pressure melting range of plagioclase and indicate that the maskelynite must form as a result of the breakdown of the highpressure plagioclase phase. As can be seen from Figure 13, the calculated shock temperatures below $1 \mathrm{Mb}$ are moderately sensitive to transition energy. For example, changing the transition energy by a factor of 2 at $500 \mathrm{~kb}$ decreases the calculated shock temperatures by approxi- 


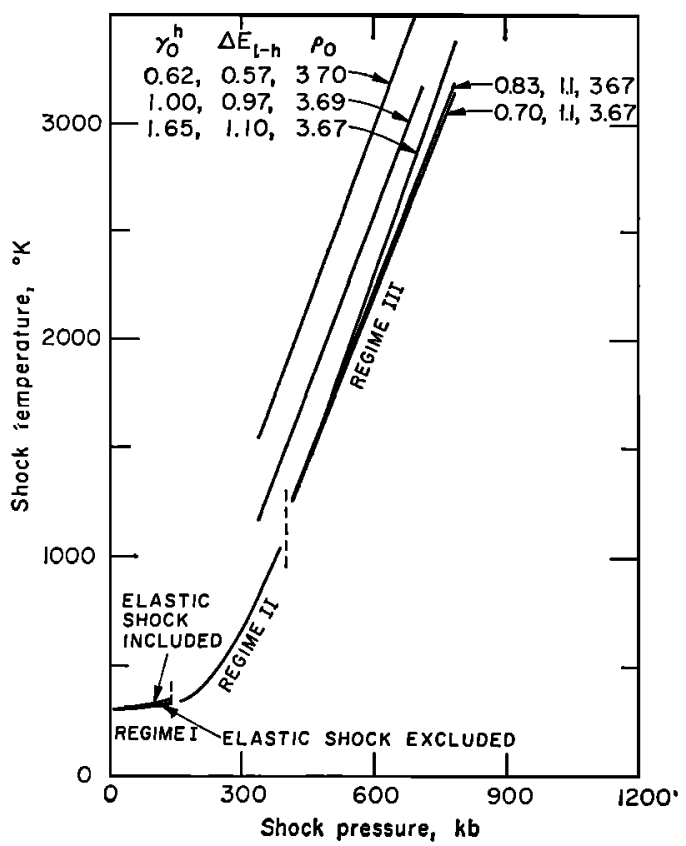

Fig. 13. Shock temperature versus shock pressure for plagioclase. Calculations including and excluding the elastic shock; for various assumed values of $\gamma_{0}{ }^{n}, \Delta E_{t-h}$, and $\rho_{0}{ }^{n}$ are shown. mately $20 \%$. As the shock pressure is increased and the shock energy $\Delta E_{\mathrm{III}}$ becomes large when compared with $\Delta E_{\imath_{-}}$, the effect of the assumed value of $\Delta E_{t_{-}}$becomes small. The calculated positions of the adiabats and isotherms are relatively insensitive to the assumed values of $\Delta E_{z_{-}}$and Grüneisen's ratio (Table 7).

The zero-pressure density and parameters of the equation of state for the isotherm (subscript $t$ ) and adiabat (subscript $s$ ) for the high-pressure phase are given in Table 9 (type $\mathrm{B}$ calculation). The adiabats of the high-pressure phases centered at standard temperature and pressure conditions are shown in Figure 14. As. can be seen, the calculated densities are lower than the values expected for the hollandite structure or for mixture of oxides. The parameters in the Birch-Murnaghan equation

$$
\begin{aligned}
& P=3 K_{0} {\left[\left(\frac{\rho}{\rho_{0}}\right)^{7 / 3}-\left(\frac{\rho}{\rho_{0}}\right)^{5 / 3}\right] } \\
& \cdot\left\{1-\xi\left[\left(\frac{\rho}{\rho_{0}}\right)^{2 / 3}-1\right]\right\} / 2
\end{aligned}
$$

are calculated for the isotherm and adiabat.

\begin{tabular}{|c|c|c|c|c|}
\hline $\begin{array}{l}\text { Specific } \\
\text { Volume } \\
V, \mathrm{~cm}^{3} / \mathrm{g}\end{array}$ & $\begin{array}{c}\text { Hugoniot } \\
\text { Pressure } \\
P_{h}, \mathrm{~kb}\end{array}$ & $\begin{array}{c}25^{\circ} \mathrm{C} \text { Isotherm } \\
\text { Pressure } \\
P_{\iota}, \mathrm{kb}\end{array}$ & $\begin{array}{c}\text { STP-Centered } \\
\text { Adiabat Pressure } \\
P_{\bullet}, \mathbf{k b}\end{array}$ & $\begin{array}{c}\text { Hugoniot } \\
\text { Temperature } \\
T_{h},{ }^{\circ} \mathrm{K}\end{array}$ \\
\hline \multicolumn{5}{|c|}{ Microcline (High-Pressure Phase) } \\
\hline $\begin{array}{l}0.239 \\
0.237 \\
0.235 \\
0.233 \\
0.231 \\
0.229 \\
0.227 \\
0.225 \\
0.223 \\
0.221\end{array}$ & $\begin{array}{l}\mathbf{3 4 7} \\
368 \\
390 \\
\mathbf{4 1 1} \\
\mathbf{4 3 4} \\
\mathbf{4 5 7} \\
\mathbf{4 8 1} \\
\mathbf{5 0 6} \\
\mathbf{5 3 1} \\
\mathbf{5 5 7}\end{array}$ & $\begin{array}{l}\mathbf{3 2 1} \\
\mathbf{3 3 7} \\
\mathbf{3 5 3} \\
\mathbf{3 7 0} \\
\mathbf{3 8 8} \\
\mathbf{4 0 5} \\
\mathbf{4 2 3} \\
\mathbf{4 4 2} \\
\mathbf{4 6 1} \\
\mathbf{4 8 0}\end{array}$ & $\begin{array}{l}324 \\
341 \\
357 \\
374 \\
392 \\
409 \\
428 \\
447 \\
466 \\
486\end{array}$ & $\begin{array}{r}967 \\
1073 \\
1213 \\
1333 \\
1458 \\
1590 \\
1729 \\
1874 \\
2026 \\
2185\end{array}$ \\
\hline \multicolumn{5}{|c|}{ Oligoclase (High-Pressure Phase) } \\
\hline $\begin{array}{l}0.240 \\
0.236 \\
0.232 \\
0.228 \\
0.224 \\
0.220 \\
0.216\end{array}$ & $\begin{array}{l}336 \\
389 \\
444 \\
504 \\
567 \\
634 \\
705\end{array}$ & $\begin{array}{l}298^{b}(281)^{c} \\
339(320) \\
381(362) \\
425(407) \\
472(454) \\
523(503) \\
575(556)\end{array}$ & $\begin{array}{l}302^{b}(284)^{a} \\
342(325) \\
386(368) \\
431(413) \\
479(460) \\
529(510) \\
583(563)\end{array}$ & $\begin{array}{l}1165^{b}(1541)^{c} \\
1417(1829) \\
1729(2119) \\
2047(2437) \\
2398(2784) \\
2747(3161) \\
3167(3571)\end{array}$ \\
\hline
\end{tabular}

TABLE 7. Calculated Isotherms, Adiabats, and Shock Temperatures

- $\Delta E_{l-h}=1.27 \times 10^{10} \mathrm{ergs} / \mathrm{g}$.

${ }^{b} \Delta E_{l-h}=0.97 \times 10^{10} \mathrm{ergs} / \mathrm{g}$.

- $\Delta E_{l-\Lambda}=0.57 \times 10^{10} \mathrm{ergs} / \mathrm{g}$. 
TABLE 8. Calculated Postshock Temperatures

\begin{tabular}{cccccc}
\hline $\begin{array}{c}\text { Shock } \\
\text { Pressure, } \\
\text { kb }\end{array}$ & $\begin{array}{c}\text { Mass Fraction, } \\
\text { High-Pressure } \\
\text { Phase }\end{array}$ & $\begin{array}{c}\gamma_{0} \rho_{0}, \\
\mathbf{g} / \mathrm{cm}^{3}\end{array}$ & $\begin{array}{c}\mathbf{T}_{h}, \\
{ }^{\circ} \mathbf{K}\end{array}$ & $\begin{array}{c}\text { Postshock } \\
\text { Volume, } \\
\text { g/cm }\end{array}$ & $\begin{array}{c}\text { Postshock } \\
\text { Temperature, } \\
{ }^{\circ} \mathrm{K}\end{array}$ \\
\hline 180 & 0.25 & 1.55 & 350 & $0.363-.379$ & $300-308$ \\
272 & 0.61 & 2.01 & 573 & $0.342-.428$ & $402-479$ \\
417 & 1.0 & 3.0 & 1,026 & $0.377-.413$ & $600-668$ \\
\hline
\end{tabular}

Here $K_{0}$ is the zero-pressure bulk modulus. The subscripts $s$ and $t$ denote the parameter for the adiabat and isotherm. We note that the values of $K_{0,}$ and $K_{0}$, and $\xi_{t}$ and $\xi_{0}$ for oligoclase $\left(A n_{12}\right)$ lie between the values inferred from the anorthosite $\left(A n_{40}\right)$ and albitite $\left(A n_{12}\right)$ data above 330 and $400 \mathrm{~kb}$ of McQueen et al. [1967]. The systematics of these parameters of the equation of state are discussed in Ahrens et al. [1969]. Because of the fewer data for microcline, it is not clear whether the lower inferred zeropressure density and hence bulk moduli are significant. The fact that the densities obtained for all the high-pressure phases of feldspars are significantly lower than $\sim 3.85 \mathrm{~g} / \mathrm{cm}^{3}$, obtained by Ringwood et al. [1967] for the hollandite structure of $\mathrm{KAlSi}_{3} \mathrm{O}_{8}$, suggests that the material formed at high shock pressures may not be completely converted to this structure.

\section{Conclusions}

Oligoclase and microcline have Hugoniot elastic limits (HEL) of 40-55 and 80-85 kb, respectively. The value of the HEL increases slightly with increasing driving shock pressure. The associated elastic shock velocities range from 6.8 to $7.6 \mathrm{~mm} / \mu$ sec and from 7.1 to 7.6 $\mathrm{mm} / \mu$ sec. These values are 5 to $10 \%$ greater than the corresponding zero-pressure longitudinal elastic velocities. Above the HEL, the Hugoniot curves indicate a transition region of anomalously high compressions extending to $\sim 300$ to $\sim 400 \mathrm{~kb}$ for microcline and oligoclase, respectively. Over this pressure range it appears that the material produced at states of successively higher shock pressure consists of a mixture of the starting material and successively greater proportions of high-pressure poly$\operatorname{morph}(\mathrm{s})$.

The results of static high pressure quenching experiments [Ringwood et al., 1967] on microcline and $\mathrm{NaAlGe}_{3} \mathrm{O}_{8}$, which is isostructural with albite, and $\mathrm{KAlGe}_{3} \mathrm{O}_{3}$ [Kune et al., 1966] indicate that at high pressure $\left(\sim 120 \mathrm{~kb}\right.$ and $\left.1000^{\circ} \mathrm{C}\right)$ these feldspars transform into the rutile-type hollandite structure with zero-pressure density of $\sim 3.85 \mathrm{~g} / \mathrm{cm}^{3}$. Although it appears likely that the feldspars transform into this structure under shock compression, the zero-pressure density of the high-pressure phases inferred from the present data for microcline and oligoclase, as well as from the data obtained by McQueen et al. [1967], (Wang [1967], Anderson and Kanamori [1968], and Ahrens et al. [1969]) for

TABLE 9. Equation of State Parameters, High-Pressure Phase

\begin{tabular}{|c|c|c|c|c|c|}
\hline Material & $\begin{array}{c}\text { Zero-Pressure } \\
\text { Density } \\
\rho_{0} \\
\text { g/cm } \\
\text { (cm }\end{array}$ & $\begin{array}{c}\text { Zero-Pressure } \\
\text { Adiabatic } \\
\text { Bulk Modulus } \\
K_{0_{a s}} \\
\text { kb }\end{array}$ & $\xi$. & $\begin{array}{c}\text { Zero-Pressure } \\
\text { Isothermal } \\
\text { Bulk Modulus } \\
K_{\text {ot }}, \\
\text { kb }\end{array}$ & $\xi_{t}$ \\
\hline Oligoclase (Muskwa Lake) & 3.69 & 2198 & 1.60 & 2177 & 1.62 \\
\hline Microcline (Ontario) & 3.52 & 1563 & 1.47 & 1553 & 1.49 \\
\hline Albitite (Sylmar) ${ }^{a}$ & 3.81 & 2550 & 1.63 & 2524 & 1.65 \\
\hline Anorthosite (Tahawus)a & 3.71 & $2084^{b}$ & 1.20 & $2086^{b}$ & 1.20 \\
\hline
\end{tabular}

- McQueen et al. [1967].

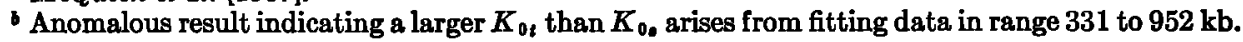




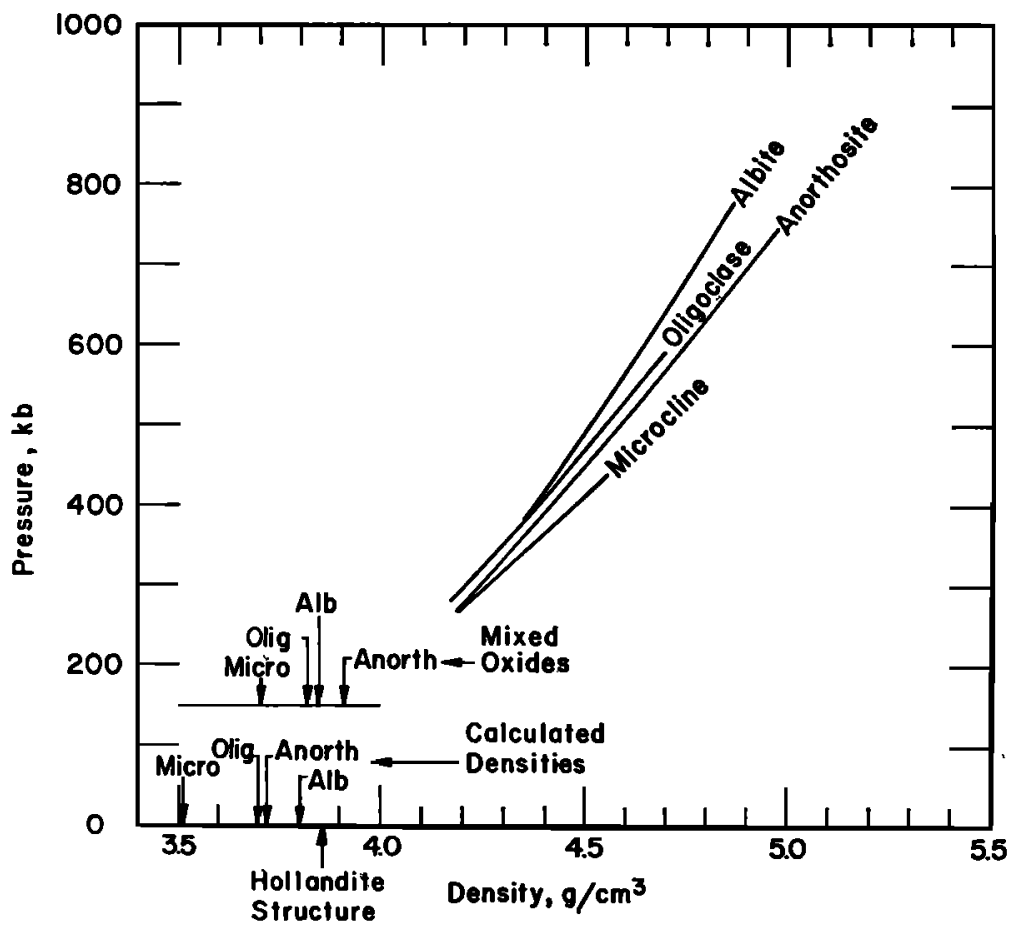

Fig. 14. Calculated adiabats for high-pressure phases of feldspars.

the albitite and anorthosite indicate substantially lower values $\left(3.5\right.$ to $\left.3.7 \mathrm{~g} / \mathrm{cm}^{3}\right)$. The low values for the zero-pressure densities for the hollandite structure of the feldspars inferred from the shock results probably arise from incomplete conversion to the high-pressure phase.

A series of shock reflection experiments were performed that generated release adiabat curves centered at 180,272 , and $417 \mathrm{~kb}$. The $180-\mathrm{kb}$ adiabat gave postshock densities of 2.64 to $2.76 \mathrm{~g} / \mathrm{cm}^{3}$. This range is slightly higher than the starting density of 2.64 to $2.65 \mathrm{~g} / \mathrm{cm}^{3}$. At 272 and $417 \mathrm{~kb}$ the postshock densities appear lower than the starting density. The shape of the release adiabat curves indicate that, although $\sim 15 \%$ of the high-pressure phase forms at $180 \mathrm{~kb}$, some of the high-pressure phase(s) is immediately reconverted so that probably less than $7 \%$ remains on pressure release. The release adiabats centered at 272 and $417 \mathrm{~kb}$ are initially steeper than the Hugoniot curve. This indicates that these adiabats reflect the pressure-volume behavior characteristic of the high-pressure phase material whereas the anomalously low postshock densities indicate that at zero-pressure most or all of the high. pressure phase material has reverted to the amorphous low-density form of plagioclase, maskelynite. These results as well as the low calculated postshock temperatures $\left(600^{\circ}-700^{\circ} \mathrm{C}\right.$ on release from $417 \mathrm{~kb}$ ) suggest that material of feldspar composition recovered from meteorite impact or from laboratory shock experiments was produced via initial conversion of feldspar to hollandite phase (during shock compression) and then by reversion to maskelynite on pressure release. These results should not, however, preclude the occurrence of some hollandite phase material in feldspars shocked to high pressure.

\section{APPENDIX}

The particle velocity determination (for the immersed foil cell) depends on the reflecting foil's achieving the particle velocity of the surrounding liquid (via a series of internal wave reflections) in a time short in comparison to the resolution time of the streak camera $\left(10^{-s} \mathrm{sec}\right)$. The foil then behaves like a particle of liquid whose motion is directly monitored. The dis- 
placement of the grid image on the film $x$ is related to the angle $e$ by

$$
\begin{aligned}
\frac{x}{M_{\mathrm{I}}} & =n_{0} h \sin e\left(1-n_{0}{ }^{2} \sin ^{2} e\right)^{-1 / 2} \\
& +r_{0} n_{0} \sin e\left(n_{0}{ }^{2}-n_{0}{ }^{2} \sin ^{2} e\right)^{-1 / 2} \\
& +\left(r-r_{g}\right) \tan e
\end{aligned}
$$

$h, r$, and $r_{g}$ are defined in Figure 15. The indices of refraction of the unshocked and shocked liquid are $n_{0}$ and $n_{1}$, the index of refraction of the glass is $n_{\theta}$, and the grid image magnification $M_{I}$ is measured at, and in the plane of the image of the grid. Here $e$ (Figure 15 ) is related to the foil turning angle $\beta$ and the initial foil angle $\alpha$ by

$$
\begin{aligned}
\beta=\alpha- & \frac{1}{2}\left\{\sin ^{-1}\left(\frac{n_{0}}{n_{1}} \sin \alpha\right)\right. \\
+ & \left.\sin ^{-1}\left[\frac{n_{0}}{n_{1}} \sin (\alpha-e)\right]\right\}
\end{aligned}
$$

Here $\beta$ is related to the liquid particle velocity by

$$
u_{1}=U_{1} \frac{\sin \beta}{\sin \alpha \cos (\alpha-\beta)}
$$

To obtain the particle velocity from simultaneous solutions of equations $1 A-3 A$ (earlier solutions were obtained by using small angle

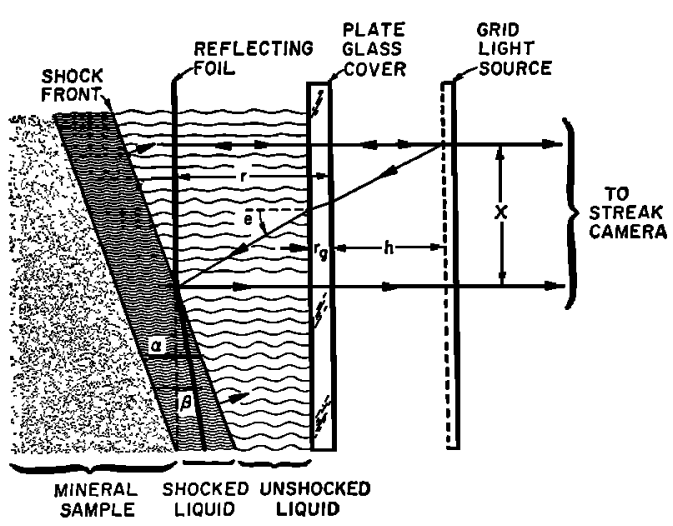

Fig. 15. Diagrammatic cross section, immersed foil release adiabat experiment. On interaction with shock wave, reflecting foil (initially at an angle $\alpha$ to sample surface) is rotated through angle $\beta$. Rotation, with resulting light ray refraction and reflection effects, causes light source image to be displaced a distance $x$, which is recorded by camera.
TABLE 10. Constants in Index of RefractionParticle Velocity Relation

\begin{tabular}{lccc}
\hline & & $\begin{array}{c}k_{1}{ }^{a} \\
\mu \mathrm{sec} / \mathrm{mm}\end{array}$ & $\begin{array}{c}k_{2}{ }^{a} \\
(\mu \mathrm{sec} / \mathrm{mm})^{2}\end{array}$ \\
\hline Glycerol & 1.469 & 0.165 & -0.0197 \\
Ethanol & 1.362 & 0.168 & -0.0180 \\
\hline
\end{tabular}

- Taken from data of Rosenberg and Petersen [1969] and Ahrens and Ruderman [1966].

approximations [Ahrens and Ruderman, 1966]), an additional relation between $n_{1}$ and $\rho$ (the density of the liquid behind the shock) or, equivalently, between $n_{1}$ and $u_{1}$

$$
n_{1}=n_{1}\left(u_{1}\right)
$$

is required. To formulate this relation, the index of refraction must be obtained from independent experiments in which the particle velocity is measured by another method and equations $1 A-3 A$ are solved for $n_{1}$ instead of $u_{1}$. To accomplish this, experiments are conducted in which immersed foil assemblies are directly mounted on driver plates, plane shocks are driven into the assemblies, and the resulting shocked state in the liquid is determined by the impedance match method.

The index of refraction determined in this manner is expressed in the empirical form

$$
n_{1}=n_{0}+k_{1} u_{1}+k_{2} u_{1}^{2}
$$

The constants used for glycerol and ethanol are given in Table 10.

Acknowledgment. We greatly appreciate the help of E. C. T. Chao, U.S. Geological Survey, in providing encouragement as well as specimens and analyses of the oligoclase material. We have profited from discussions of various aspects of this work with A. E. Ringwood, D. L. Anderson, and $\mathrm{O}$. F. Tuttle as well as from the suggestions of one of the reviewers.

This research was supported in part by the National Aeronautics and Space Administration under NASr-49(24) and the Defense Atomic Support Agency under DASA 01-68-C-0069. The experiments were performed at Stanford Research Institute.

\section{REFERENCES}

Ahrens, T. J., High-pressure electrical behavior and equation of state of magnesium oxide from shock wave measurements, J. Appl. Phys., B7, 2530-2541, 1966. 
Ahrens, T. J., D. L. Anderson, and A. E. Ringwood, The equation of state and crystal structures of high-pressure phases of silicates and oxides, Rev. Geophys., (in press), 1969.

Ahrens, T. J., and G. E. Duvall, Stress relaxation behind elastic shock waves in rock, J. Geophys. Res., 71, 4349-4360, 1966.

Ahrens, T. J., and V. G. Gregson, Jr., Shock compression of crustal rocks: Data for quartz, calcite, and plagioclase rocks, J. Geophys. Res., $69,4839-4873,1964$.

Ahrens, T. J., and M. H. Ruderman, Immersedfoil method for measuring shock wave profiles in solids, J. Appl. Phys., s7, 4758-4765, 1966.

Ahrens, T. J., and J. T. Rosenberg, Shock metamorphism: Experiments on quartz and plagioclase, in Shock Metamorphism of Natural Materials, edited by B. M. French and N. M. Short, pp. 59-81, Mono Press, Baltimore, Md., 1968.

Alexandrov, K. S., and T. V. Ryzhova, Elastic properties of rock-forming minerals, 3, Feldspars, Bull. USSR Acad. Sci., Geophys. Ser., no. 2, 129-131, 1962.

Anderson, Don L., A seismic equation of state, Geophys. J. Roy. Astron. Soc., 18, 9-30, 1967.

Anderson, D. L., and H. Kanamori, Shock wave equations of state for rocks and minerals, $J$. Geophys. Res., 78, 6477-6502, 1968.

Anderson, O. L., Some remarks on the volume dependence of the Grüneisen parameter, $J$. Geophys. Res., 73, 5187-5194, 1968.

Binns, R. A., Stony meteorites bearing maskelynite, Nature, 1111-1112, March 18, 1967.

Bunch, T. E., M. R. Dence, and A. J. Cohen, Natural terrestrial maskelynite, $\boldsymbol{A m}$. Mineralogist, 52, 244-253, 1967.

Chao, E. C. T. Shock effects in certain rockforming minerals, Science, 156, 192-202, 1967.

Cowperthwaite, M., and T. J. Ahrens, Thermodynamics of the adiabatic expansion of a mixture of two phases, $A m$. J. Phys., 35, 951-955, 1967.

DeCarli, P. S., and J. C. Jamieson, Formation of an amorphous form of quartz under shock conditions, J. Chem. Phys., 31, 1675-1676, 1959.

Doran, D. G.. Measurement of shock pressures in solids, in High Pressure Measurement, edited by A. A. Giardini and E. C. Lloyd, Butterworths, Washington, D. C., 1963.
Duke, M. B., Dense plagioclase glass (maskelynite) from Shergotty, in part B, Crater Investigations, meteorite, U.S. Geolog. Surv. Astrogeologic Studies, Ann. Progress Rept., 10-20, 1964.

Duke, M. B., and L. T. Silver, Petrology of eucrites, howardites, and mesosiderites, Geochim. Cosmochim. Acta, 31, 1637-1665, 1967.

Huang, Y. K., On static and dynamic compressibilities of Debye solids at high pressures, $J$. Chem. Phys., 46, 4570-4575, 1967.

Kume, S., T. Matsumoto, and M. Koizumi, Dense form of germanate orthoclase $\left(\mathrm{KAlGe}_{8} \mathrm{O}_{8}\right), J$. Geophys. Res., 71, 4999-5000, 1966.

McQueen, R. G., S. P. Marsh, and J. N. Fritz, Hugoniot equation of state of twelve rocks, $J$. Geophys. Res., 7\%, 4999-5036, 1967.

Milton, D. J., and P. S. DeCarli, Maskelynite: Formation by explosive shock, Science, 140, 670-671, 1963.

Rice, M. H., R. G. McQueen, and J. M. Walsh, Compression of solids by strong shock waves, in Solid State Physics, vol. 6, edited by F. Seitz and D. Turnbull, pp. 1-63, Academic Press, New York, 1958.

Ringwood, A. E., A. F. Reid, and A. D. Wadsley, High pressure transformation of alkali aluminosilicates and aluminogermanates, Earth Planetary Sci. Letters, 3, 38-40, 1967.

Rosenberg, T. J., and C. F. Petersen, A note on the index of refraction of ethanol and glycerol under shock, to be published, 1969.

Stöffler, D., Deformation und Umwandlung von Plagioklas duch Stosswellen in der Gesteinen des Nördlinger Ries, Contr. Mineral. Petrol., 16, 51-83, 1967.

von Engelhart, W., and D. Stöfller, Stages of shock metamorphism in rocks of the Ries basin, Proc. Conf. Shock Metamorphism, edited by B. M. French and N. M. Short, pp. 159-168, Mono Press, Baltimore, Md., 1968.

Wackerle, J., Shock-wave compression of quartz, J. Appl. Phys., 3s, 922-937, 1962.

Wang, C., Phase transitions in rocks under shock compression, Earth Planetary Sci. Letters, 8, 107-110, 1967.

(Received September 6, 1968; . revised January 27, 1969.) 